in vivo $35: 3391-3399(2021)$

doi:10.21873/invivo.12638

\title{
Paclitaxel and Carboplatin Versus Cisplatin and 5-Fluorouracil in Concurrent Chemoradiotherapy in Patients With Esophageal Cancer
}

\author{
PO-HSU SU ${ }^{1}$, SHUN-WEN HSUEH ${ }^{1}, \mathrm{CHEN}^{-K A N}$ TSENG ${ }^{2}$, MING-MO HO ${ }^{3}$, PO-JUNG SU ${ }^{3}$, \\ CHIA-YEN HUNG ${ }^{3,4}$, KUN-YUN YEH ${ }^{1}$, PEI-HUNG CHANG $^{1}$, YU-SHIN HUNG ${ }^{3}$, \\ YA-WEN HO ${ }^{3}$, YU-CHING LIN ${ }^{5}$ and WEN-CHI CHOU ${ }^{3}$ \\ ${ }^{1}$ Department of Oncology, Chang Gung Memorial Hospital at Keelung, Keelung, Taiwan, R.O.C.; \\ ${ }^{2}$ Department of Division of Radiation Oncology, \\ Chang Gung Memorial Hospital at Linkou and College of Medicine, \\ Chang Gung University, Taoyuan, Taiwan, R.O.C.; \\ ${ }^{3}$ Division of Hematology and Oncology, Department of Internal Medicine, \\ Chang Gung Memorial Hospital at Linkou and College of Medicine, \\ Chang Gung University, Taoyuan, Taiwan, R.O.C.; \\ ${ }^{4}$ Division of Hematology and Oncology, Department of Internal Medicine, \\ Mackay Memorial Hospital, Taipei, Taiwan, R.O.C.; \\ ${ }^{5}$ Department of Medical Imaging and Intervention, \\ Chang Gung Memorial Hospital at Keelung, Keelung, Taiwan, R.O.C.
}

\begin{abstract}
Background/Aim: Cisplatin with 5-fluouracil (Cis/5Fu) and paclitaxel with carboplatin (Pac/Car) are common regimens used in concurrent chemoradiotherapy (CCRT) for patients with locally advanced esophageal cancer (EC). Here, we aimed to compare the survival outcomes and treatment-related toxicities between these regimens in neoadjuvant CCRT in patients with locally advanced EC. Patients and Methods: One hundred and thirty-six patients with locally advanced EC (98\% squamous cell carcinoma) were prospectively recruited between 2016 and 2017 in a nonrandomized manner. Patients were categorized into two groups according to the chemotherapeutic agents administered (Pac/Car group, $n=87$; Cis/5Fu group, $n=47$ ) in CCRT to compare the survival outcome and severe adverse event ( $S A E)$ incidence. Results: Forty-two patients $(85.7 \%)$ and 80 patients $(91.4 \%)$ in the Cis/5Fu and Pac/Car groups completed pre-
\end{abstract}

This article is freely accessible online.

Correspondence to: Wen-Chi Chou, Division of Hematology and Oncology, Department of Internal Medicine, Chang Gung Memorial Hospital, No. 5, Fu-Hsing Street, Kwei-Shan Shiang, Taoyuan, Taiwan, R.O.C. Tel: +8863281200 Ext 2517, Fax: +88633285818 , e-mail: wenchi3992@yahoo.com.tw

Key Words: Concurrent chemoradiotherapy, carboplatin, cisplatin, esophageal cancer, outcome. planned CCRT ( $p=0.26)$, respectively. The Cis/5Fu group presented a higher incidence of non-hematological $s A E$ than the Pac/Car group (69.45\% vs. $51.7 \%$, p=0.049). Patients in the Pac/Car group showed a higher rate of surgical resection than those in the Cis/5Fu group (49.4\% vs. $22.4 \%, p<0.001)$. After a median follow-up duration of 22.0 months (range=1.9-31.8), the 2-year survival rate was $56.9 \%$ for patients in the Pac/Car group and $28.7 \%$ for the Cis/5Fu group. The hazard ratio (HR) of overall survival was 0.45 (95\%CI=0.28-0.72, $p=0.001)$ in the comparison between the groups. Conclusion: Overall, neoadjuvant CCRT with Pac/Car is associated with a better survival outcome, higher surgical resection rate, and better safety profiles than Cis/5Fu in patients with locally advanced EC.

Esophageal cancer (EC) is a highly fatal disease (1). Surgical resection and definitive concurrent chemoradiotherapy (CCRT) are the most effective curative treatment options for patients with early-stage esophageal cancer (2). With radical surgery, it is difficult to achieve complete resection; moreover, EC is associated with a high recurrence rate and a postoperative 5-year survival rate of less than $15 \%$ in patients with locally advanced EC $(3,4)$. The unsatisfactory treatment outcome with surgery alone promotes the rationale of multimodal treatment, using preoperative chemoradiotherapy to i) downstage tumors, ii) increase complete resection rate, and iii) improve survival outcome in patients with locally advanced EC $(3,4)$. 
The positive role of neoadjuvant CCRT in patients with locally advanced EC has been well established. Cisplatin and 5-fluoruracil ( $\mathrm{Cis} / 5 \mathrm{Fu}$ ) have been commonly used concurrently with radiotherapy for patients with unresectable locally advanced EC since 1992, when the RTOG 85-01 study showed a significant survival advantage with CCRT and a Cis/5Fu regimen compared to radiotherapy alone (5). Later, in 2012, the CROSS trial demonstrated a significant survival benefit and lower toxicity profiles of preoperative CCRT with paclitaxel and carboplatin (Pac/Car) followed by surgery compared to surgery alone (6). Since then, the Pac/Car regimen has become another standard regimen for patients with locally advanced EC in the preoperative CCRT setting (7).

Both $\mathrm{Cis} / 5 \mathrm{Fu}$ and $\mathrm{Pac} / \mathrm{Car}$ are popular regimens in CCRT settings for patients with locally advanced esophageal cancer; however, no randomized phase III study has directly compared the treatment efficacy and toxicity profiles of these two regimens. The $\mathrm{Cis} / 5 \mathrm{Fu}$ regimen has advantages of easier accessibility and lower financial burden. On the other hand, the $\mathrm{Pac} / \mathrm{Car}$ regimen is convenient to use in clinical practice because it can be easily administered in outpatient clinics and is associated with less renal toxicity than cisplatin (7). There are only a few phase II studies and retrospective reports showing a comparable survival outcome between the $\mathrm{Cis} / 5 \mathrm{Fu}$ and $\mathrm{Pac} / \mathrm{Car}$ regimens (8-11). Previous studies have shown that Pac/Car has the advantage of less toxicity than $\mathrm{Cis} / 5 \mathrm{Fu}$ in the preoperative or definitive CCRT setting for patients with locally advanced EC (9). However, the heterogeneity and small patient number make it difficult to conclude on the preference of the regimen in this patient group. In this study, we aimed to compare the survival outcome and the treatment-related toxicity between $\mathrm{Cis} / 5 \mathrm{Fu}$ and Pac/Car with neoadjuvant CCRT in patients with locally advanced EC. This was a prospective observational study with the choice of the two treatment regiments, assigned based on the decision of clinicians/patients.

\section{Patients and Methods}

Patient selection. In this prospective observational study, we consecutively recruited patients between August 2016 and December 2017 from CGMH in Taiwan. The eligibility criteria were: i) patients aged 20 years or older, ii) histologically-proven locally advanced EC, and iii) treatment with neoadjuvant CCRT as the first-line antitumor therapy. A locally advanced tumor was defined as any tumor $\geq \mathrm{T} 2$ classification, or any regional nodalpositive tumor. The exclusion criteria were: i) metastatic disease, ii) management with chemotherapy or radiotherapy alone, and iii) inability to provide informed consent for any reason. Tumor staging was performed according to the seventh edition of the American Joint Committee on Cancer (AJCC) staging system (12). The study protocol was approved by the institutional review board of CGMH (No: 1608080002) and was conducted according to the principles expressed in the Declaration of Helsinki. Figure 1 presents the CONSORT diagram of this study.
Neoadjuvant chemoradiotherapy. All eligible patients received either CCRT with $\mathrm{Cis} / 5 \mathrm{Fu}$ (cisplatin $100 \mathrm{mg} / \mathrm{m}^{2}$ and 5-fluouracil 1,000 $\mathrm{mg} / \mathrm{m}^{2} / \mathrm{d}$ for 4 days at weeks 1 and 5), concurrent with radiotherapy $1.8 \mathrm{~Gy} \times 28$ fractions for a total of $50.4 \mathrm{~Gy}$ (13) or Pac/Car (paclitaxel $50 \mathrm{mg} / \mathrm{m}^{2}$ and carboplatin area under the curve of $2 \mathrm{mg} / \mathrm{ml} / \mathrm{min}$ on day 1 weekly over 5 weeks, concurrent with intensity-modulated or arc technique radiotherapy $1.8 \mathrm{~Gy} \times 23$ fractions for a total of 41.4 Gy) (6) to the tumor bed and regional lymphatics. Local booster radiotherapy with 5-23.4 Gy to the primary tumor and the associated nodal area was provided to patients who either did not undergo surgical resection or had positive pathological lymph node metastases after surgery (6). The patients were informed about the differences in the clinical and economic benefits of the two regimens. $\mathrm{Cis} / 5 \mathrm{Fu}$ has the benefits of better accessibility and lower cost as it would be covered by Taiwan's national health insurance, whereas Pac/Car has a lower toxicity profile. The two regimens were suggested by the physicians to the patients, and the final treatment choice was made by the patients.

The patients underwent a computed tomography (CT) scan and esophagogastroduodenoscopy (EGD) for tumor restaging within 4 weeks after the completion of radiotherapy. After the completion of treatment, the resectability of tumor was evaluated by a specialized tumor board, based on the response of tumors and the clinical condition of the patients. If the residual tumor was deemed resectable by the board and the patient provided an informed consent, the patient underwent minimally invasive transthoracic esophageactomy (Ivor-Levis) (14) with mediastinal lymphadenectomy within 4-8 weeks after the completion of CCRT.

Evaluation of response and toxicity. Response to CCRT was assessed by restaging CT scan and EDG according to RECIST criteria, version 1.0. For patients who underwent surgical resection, pathological response was assessed according to the following four tumor regression grades: i) grade 1 , no evidence of vital residual tumor cells (pathological complete response); ii) grade 2, less than $10 \%$; iii) grade $3,10 \%-50 \%$; iv) grade 4 , more than $50 \%$ vital residual tumor cells (15). Resection was defined as R0 resection when both macroscopic and microscopic margins were removed with negative margins. R1 and R2 resection were defined as positive microscopic (tumor $\leq 1 \mathrm{~mm}$ from any margin) and macroscopic residual disease of the surgical margin, respectively (16).

CCRT-related toxicity was graded according to the Common Toxicity Criteria (CTC) of the National Cancer Institute (NCI), version 3 (17). Any grade III or higher toxicity was defined as severe adverse events (AEs). Patients who received less than $90 \%$ of the protocol-specified radiotherapy dose or full cycles of chemotherapy due to any cause were considered to have incomplete CCRT. Overall survival (OS) was defined as the period from the beginning of CCRT treatment to the day of death from any cause and the last day of follow-up.

Statistical analysis. Descriptive analyses were performed to summarize the patient and tumor characteristics. Kruskal-Wallis test for continuous and ordinal variables, and chi-square (or Fisher's exact test) for categorical variables were used for in-group comparisons. The survival outcome was calculated according to the Kaplan-Meier method. Log-rank test was used to determine significant differences between the survival curves. A Cox regression model was used to estimate the hazard ratio (HR) for variables associated with OS. SPSS 17.0 software (SPSS Inc., 


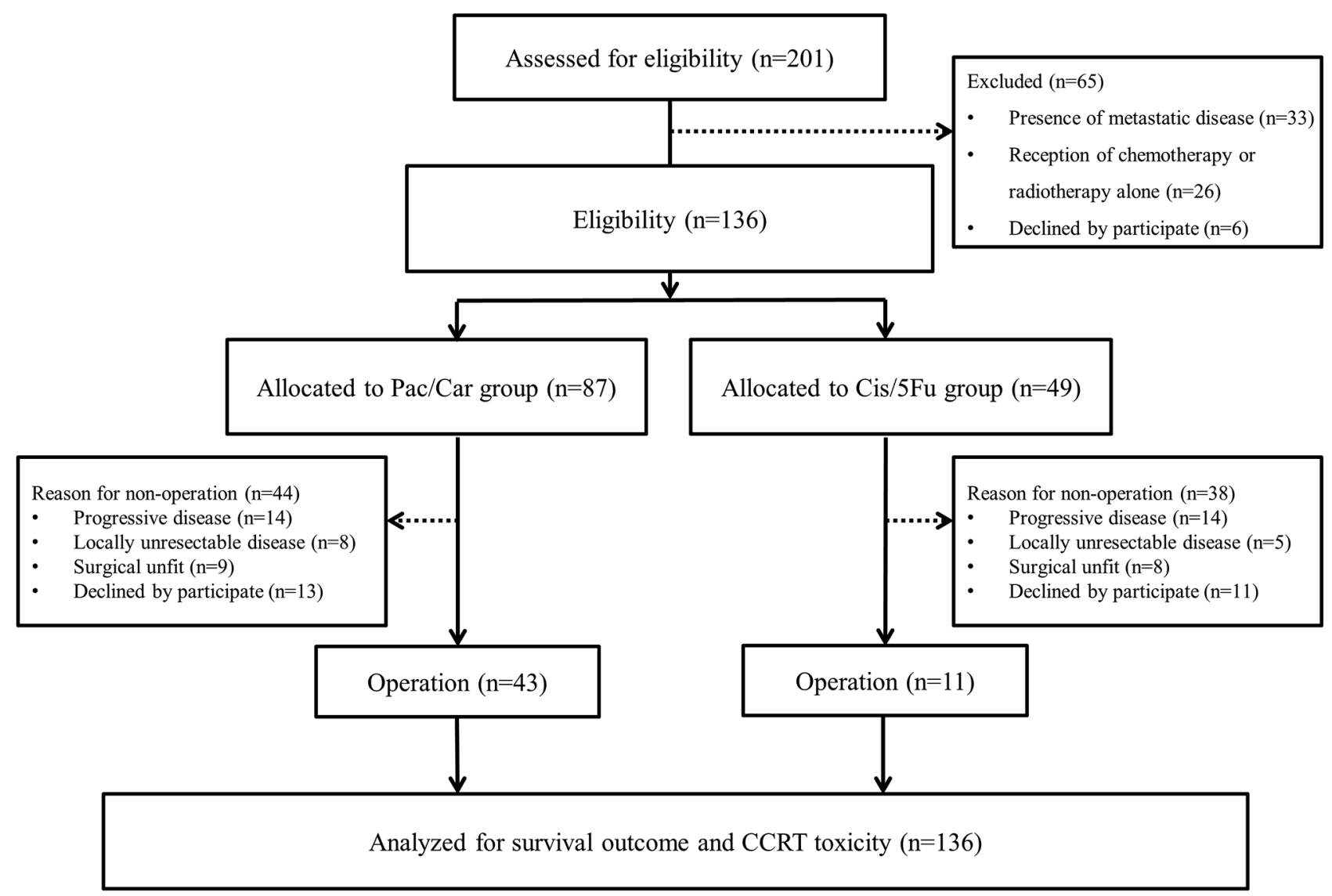

Figure 1. CONSORT diagram of the study. Cis/5Fu: Cisplatin with 5-fluouracil; Pac/Car: paclitaxel with carboplatin; CCRT: concurrent chemoradiotherapy.

Chicago, IL, USA) was used for statistical analyses. All statistical assessments were two-sided, and results with a $p$-Value of $<0.05$ were considered statistically significant.

\section{Results}

Patient and tumor characteristics. One hundred and thirtysix patients were included in the study; 49 and 87 were treated with the $\mathrm{Cis} / 5 \mathrm{Fu}$ and $\mathrm{Pac} / \mathrm{Car}$ regimens, respectively. No significant differences were observed between the groups with respect to age, sex, educational level, lifestyle habits with alcohol consumption, cigarette smoking, betel nut chewing, Eastern Cooperative Oncology Group (ECOG) performance, comorbidity, tumor location, tumor length, and clinical $\mathrm{T}$ - and N-classification. The majority of the histological types (98\%) were squamous cell carcinoma (Table I).

Treatment completion rate and toxicity of concurrent chemoradiotherapy. Forty-two patients $(85.7 \%)$ in the $\mathrm{Cis} / 5 \mathrm{Fu}$ group and 80 patients $(91.4 \%)$ in the Pac/Car group completed CCRT. There were no significant differences in CCRT, radiotherapy, or chemotherapy incompletion rates between the groups (Table II).

Grade 3 or higher hematological and non-hematological toxicities were observed in 25 patients $(51.0 \%)$ and 34 patients $(69.4 \%)$ in the $\mathrm{Cis} / 5 \mathrm{Fu}$ group, respectively, and 44 patients $(50.6 \%)$ and 45 patients $(51.7 \%)$ in the Pac/Car group, respectively (Table III). There were no significant differences in the incidence of hematological sAEs between the $\mathrm{Cis} / 5 \mathrm{Fu}$ and $\mathrm{Car} / \mathrm{Pac}$ groups. Patients treated with $\mathrm{Cis} / 5 \mathrm{Fu}$ presented a higher incidence of any nonhematological sAE than those in the Pac/Car group $(p=0.049)$, and the most noticeable difference was in the incidence of mucositis $(42.9 \%$ vs. $23.9 \%, p=0.020)$ and hypokalemia $(18.4 \%$ vs. $4.6 \%, p=0.014)$.

Tumor response and surgical resection. The objective response rate to CCRT is presented in Table IV. The major reason why the patients did not receive surgical resection was progressive disease or locally unresectable disease in both groups (Figure 1). The tumor control rate was higher in 
Table I. Patient characteristics.

\begin{tabular}{|c|c|c|c|}
\hline Variable & $\begin{array}{c}\mathrm{Cis} / 5 \mathrm{Fu}(\mathrm{n}=49) \\
\mathrm{n}(\%)\end{array}$ & $\begin{array}{c}\mathrm{Pac} / \mathrm{Car}(\mathrm{n}=87) \\
\mathrm{n}(\%)\end{array}$ & $p$-Value \\
\hline Median age, years (range) & $56(36-77)$ & $56(28-82)$ & 0.75 \\
\hline Gender & & & 0.055 \\
\hline Male & $48(98.0)$ & $76(87.4)$ & \\
\hline Female & $1(2.0)$ & $11(12.6)$ & \\
\hline Education & & & 0.51 \\
\hline Nil/elementary & $11(22.4)$ & $24(27.6)$ & \\
\hline Junior high school & $23(46.9)$ & $32(36.8)$ & \\
\hline $\begin{array}{l}\text { Senior high school } \\
\text { or higher }\end{array}$ & $15(30.6)$ & $31(35.6)$ & \\
\hline Marriage & & & 0.12 \\
\hline Yes & $34(69.4)$ & $72(82.8)$ & \\
\hline No & $15(30.6)$ & $15(17.2)$ & \\
\hline Alcohol consumption & & & 0.26 \\
\hline No & $1(2.0)$ & $7(8.0)$ & \\
\hline Yes & $48(98.0)$ & $80(92.0)$ & \\
\hline Cigarette smoking & & & 0.055 \\
\hline No & $1(2.0)$ & $11(12.6)$ & \\
\hline Yes & $48(98.0)$ & $76(87.4)$ & \\
\hline Betelnut chewing & & & 0.56 \\
\hline No & $12(24.5)$ & $26(29.9)$ & \\
\hline Yes & $37(75.5)$ & $61(70.1)$ & \\
\hline Body mass index, $\mathrm{kg} / \mathrm{m}^{2}$ & $20.9(15.9-28.9)$ & $22.4(15.9-31.6)$ & 0.17 \\
\hline ECOG performance & & & 0.75 \\
\hline 0 & $25(51.0)$ & $50(57.5)$ & \\
\hline 1 & $23(46.9)$ & $35(40.2)$ & \\
\hline 2 & $1(2.0)$ & $2(2.3)$ & \\
\hline $\begin{array}{l}\text { Charlson comorbidity } \\
\text { index }\end{array}$ & & & 0.60 \\
\hline 0 & $20(40.8)$ & $45(51.7)$ & \\
\hline 1 & $18(36.4)$ & $16(18.4)$ & \\
\hline$\geq 2$ & $11(22.4)$ & $26(29.9)$ & \\
\hline Histological type & & & 0.71 \\
\hline $\begin{array}{l}\text { Squamous cell } \\
\text { carcinoma }\end{array}$ & $48(98.0)$ & $85(97.7)$ & \\
\hline Adenocarcinoma & $1(2.0)$ & $2(2.3)$ & \\
\hline Tumor location & & & 0.11 \\
\hline Upper & $12(24.5)$ & $13(14.9)$ & \\
\hline Middle & $18(36.7)$ & $31(35.6)$ & \\
\hline Lower & $14(28.6)$ & $20(23.0)$ & \\
\hline Overlapping & $5(10.2)$ & $23(26.4)$ & \\
\hline Tumor length & $4.8(1.6-16.0)$ & $5.0(1.0-17.0)$ & 0.72 \\
\hline Tumor stage & & & 0.38 \\
\hline 2 & $10(20.4)$ & $15(17.2)$ & \\
\hline 3 & $29(59.2)$ & $61(70.1)$ & \\
\hline $4 \mathrm{a}$ & $10(20.4)$ & $11(12.6)$ & \\
\hline Clinical T-classification & & & 0.33 \\
\hline $\mathrm{T} 1$ & $3(6.1)$ & $1(1.1)$ & \\
\hline $\mathrm{T} 2$ & $9(18.4)$ & $12(13.8)$ & \\
\hline $\mathrm{T} 3$ & $23(46.9)$ & $48(55.2)$ & \\
\hline $\mathrm{T} 4$ & $14(28.6)$ & $26(29.9)$ & \\
\hline Clinical N-classification & & & 0.12 \\
\hline No & $6(12.2)$ & $1(1.1)$ & \\
\hline N1 & $15(30.6)$ & $12(13.8)$ & \\
\hline $\mathrm{N} 2$ & $1326.5)$ & $48(55.2)$ & \\
\hline N3 & $15(30.6)$ & $26(29.9)$ & \\
\hline
\end{tabular}

Cis/5Fu: Cisplatin with 5-fluouracil; Pac/Car: paclitaxel with carboplatin; ECOG: Eastern Cooperative Oncology Group.
Table II. Incomplete treatment of chemoradiotherapy according to chemotherapeutic regimen.

\begin{tabular}{lcccc}
\hline Variable & $\begin{array}{c}\text { Overall } \\
(\mathrm{n}=136) \\
\mathrm{n}(\%)\end{array}$ & $\begin{array}{c}\mathrm{Cis} / 5 \mathrm{Fu} \\
(\mathrm{n}=49) \\
\mathrm{n}(\%)\end{array}$ & $\begin{array}{c}\mathrm{Pac} / \mathrm{Car} \\
(\mathrm{n}=87)\end{array}$ & \\
$\mathrm{n}(\%)$ & $p$-Value \\
\hline Chemoradiotherapy & $14(10.3)$ & $7(14.3)$ & $7(8.6)$ & 0.26 \\
Chemotherapy & $10(7.4)$ & $5(10.2)$ & $5(5.7)$ & 0.50 \\
Radiotherapy & $11(8.1)$ & $6(12.2)$ & $5(5.7)$ & 0.20 \\
\hline
\end{tabular}

Cis/5Fu: Cisplatin with 5-fluouracil; Pac/Car: paclitaxel with carboplatin.

the $\mathrm{Pac} / \mathrm{Car}$ group than in the $\mathrm{Cis} / 5 \mathrm{Fu}$ group $(75.9 \%$ vs. $57.1 \%, p=0.05)$. Patients in the Pac/Car group presented a higher probability of receiving surgical resection after CCRT than those in the Cis/5Fu group (49.4\% vs. 22.4\%, $p<0.001)$. Among the 43 patients in the $\mathrm{Pac} / \mathrm{Car}$ group, 33 patients (76.7\%), 8 patients (18.6\%), and 2 patients (4.7\%) achieved R0, R1, and R2 resection, respectively. Nine of the 11 patients $(81.8 \%)$ in the $\mathrm{Cis} / 5 \mathrm{Fu}$ group achieved $\mathrm{R} 0$ resection and the other 2 patients (18.2\%) achieved R1 resection. No statistical intergroup difference with respect to the resection status $(p=0.76)$, the tumor regression grade $(p=0.36)$, or surgical complications (all $p<0.05$ ) was noted (Table V).

Survival. The median follow-up was 22.0 (range=1.9-31.8) months, and $67(49.3 \%)$ patients died at the end of the follow-up. The 1- and 2-year survival rates were $71.2 \%$ and $56.9 \%$ for patients in the Pac/Car group, respectively, and $48.6 \%$ and $28.7 \%$ for patients in the $\mathrm{Cis} / 5 \mathrm{Fu}$ group, respectively (Figure 2). The HR of OS was 0.45 $(95 \% \mathrm{CI}=0.28-0.72, p=0.001)$ in the comparison between the patient groups. The adjusted HR was $0.47(95 \% \mathrm{CI}=0.28$ $0.80, p=0.005$ ) after adjusting for age, ECOG performance, stage, tumor location, and comorbidity. The adjusted HR for OS was $0.57(95 \% \mathrm{CI}=0.33-0.97, p=0.038)$ after adjusting for surgery and other clinical variables mentioned above (Table VI).

With respect to the effect of surgery on the survival outcome, we divided the patients into surgery and nonsurgery cohorts for survival comparison (Figure 3). Patients who underwent surgery in the Pac/Car group showed a trend towards a better 2-year OS (62.1\% vs. 52.4\%, $p=0.065)$ than those who did not undergo surgery. However, patients who underwent surgery in the $\mathrm{Cis} / 5 \mathrm{Fu}$ group presented a significantly higher OS (67.5\% vs. $19.2 \%, p=0.009)$ than those who did not undergo surgery. In the surgery cohort, no significant survival difference was noted in patients between the $\mathrm{Cis} / 5 \mathrm{Fu}$ and $\mathrm{Pac} / \mathrm{Car}$ groups $(p=0.86)$. However, in the non-surgery cohort, patients in the Pac/Car group presented a significantly higher survival rate than those in the Cis $/ 5 \mathrm{Fu}$ group $(p=0.010)$. 
Table III. Severe ( $\geq$ grade III) treatment-related toxicity.

\begin{tabular}{lccl}
\hline Toxicity & $\begin{array}{c}\text { Cis/5Fu (n=49) } \\
\mathrm{n}(\%)\end{array}$ & $\begin{array}{c}\text { Pac/Car (n=87) } \\
\mathrm{n}(\%)\end{array}$ & $p$-Value \\
\hline Any hematological & $25(51.0)$ & $44(50.6)$ & 0.99 \\
Thrombocytopenia & $6(12.2)$ & $9(10.3)$ & 0.78 \\
Leukopenia & $14(28.6)$ & $38(43.7)$ & 0.09 \\
Neutropenia & $14(28.6)$ & $15(17.2)$ & 0.13 \\
Neutropenic fever & $6(12.2)$ & $4(4.6)$ & 0.17 \\
Any nonhematological & $34(69.4)$ & $45(51.7)$ & $\mathbf{0 . 0 4 9}$ \\
Hypertension & $7(14.3)$ & $5(5.7)$ & 0.12 \\
Emesis & $5(10.2)$ & $7(8.0)$ & 0.76 \\
Infection & $8(16.3)$ & $15(17.2)$ & 0.99 \\
Mucositis & $21(42.9)$ & $20(23.9)$ & $\mathbf{0 . 0 2 0}$ \\
Hyperglycemia & $2(5.3)$ & $5(8.6)$ & 0.70 \\
AST/ALT elevation & $1(2.0)$ & $4(4.6)$ & 0.65 \\
Hypokalemia & $9(18.4)$ & $4(4.6)$ & $\mathbf{0 . 0 1 4}$ \\
Hyponatremia & $10(20.4)$ & $8(9.2)$ & 0.072 \\
\hline
\end{tabular}

Cis/5Fu: Cisplatin with 5-fluouracil; Pac/Car: paclitaxel with carboplatin; AST: aspartate aminotransferase; ALT: alanine aminotransferase. Significant $p$-Values are shown in bold.

Table IV. Best tumor response after concurrent chemoradiotherapy.

\begin{tabular}{lccc}
\hline & $\begin{array}{c}\mathrm{Cis} / 5 \mathrm{Fu}(\mathrm{n}=49) \\
\mathrm{n}(\%)\end{array}$ & $\begin{array}{c}\text { Pac/Car (n=87) } \\
\mathrm{n}(\%)\end{array}$ & $p$-Value \\
\hline Objective response rate & $28(57.1)$ & $66(75.9)$ & 0.050 \\
$\quad$ Complete response & $8(16.3)$ & $9(10.3)$ & \\
Partial response & $20(40.8)$ & $57(65.5)$ & \\
Stable disease & $7(14.3)$ & $7(8.0)$ & \\
Disease control rate & $35(71.4)$ & $73(83.9)$ & \\
$\quad$ Progressive disease & $14(28.6)$ & $14(16.1)$ & \\
Surgical resection & $11(22.4)$ & $43(49.4)$ & $<0.001$
\end{tabular}

Cis/5Fu: Cisplatin with 5-fluouracil; Pac/Car: paclitaxel with carboplatin.

\section{Discussion}

In our prospective observational study, patients with locally advanced EC, who received neoadjuvant CCRT with $\mathrm{Pac} / \mathrm{Car}$, presented substantially higher overall response rates, surgical resection rates, lower incidences of nonhematological toxicities, as well as better survival outcomes compared to those who received $\mathrm{Cis} / 5 \mathrm{Fu}$. Further analysis based on patients who underwent surgical resection revealed that patients who received either Pac/Car or Cis/5Fu had similar clinical benefits in terms of survival rate, tumor regression grade, and resection status. Overall, patients who were treated with $\mathrm{Cis} / 5 \mathrm{Fu}$ and did not undergo surgical resection presented the poorest survival outcome in our patient cohort. Between the regimens, Pac/Car was the
Table V. Pathological assessment for patients who received radical surgery.

\begin{tabular}{lccc}
\hline & $\begin{array}{c}\text { Cis/5Fu (n=11) } \\
\mathrm{n}(\%)\end{array}$ & $\begin{array}{c}\text { Pac/Car (n=43) } \\
\mathrm{n}(\%)\end{array}$ & $p$-Value \\
\hline $\begin{array}{l}\text { Tumor regression grade } \\
\quad \text { (pathologic complete }\end{array}$ & $4(36.4)$ & $18(41.9)$ & 0.36 \\
$\quad$ response) & $4(36.4)$ & $7(16.3)$ & \\
2 & $1(9.1)$ & $12(27.9)$ & \\
3 & $2(18.2)$ & $6(14.0)$ & \\
4 & & & 0.76 \\
Resection status & $9(81.8)$ & $33(76.7)$ & \\
R0 & $2(18.2)$ & $8(18.6)$ & \\
R1 & 0 & $2(4.7)$ & 0.88 \\
R2 & & & \\
Surgical complication & $1(9.1)$ & $1(2.3)$ & \\
Cardiovascular event & $1(9.1)$ & $2(4.7)$ & \\
Leak & 0 & $1(2.3)$ & \\
Postoperative 90 days & & & \\
mortality & & & \\
\hline
\end{tabular}

Cis/5Fu: Cisplatin with 5-fluouracil; Pac/Car: paclitaxel with carboplatin.

Table VI. Univariate and multivariate analyses for overall survival.

\begin{tabular}{lccc}
\hline $\begin{array}{l}\text { Chemotherapeutic } \\
\text { regimen }\end{array}$ & $\begin{array}{c}\mathrm{HR} \\
(95 \% \mathrm{CI})\end{array}$ & $\begin{array}{c}\text { Adjusted } \mathrm{HR}^{\mathrm{a}} \\
(95 \% \mathrm{CI})\end{array}$ & $\begin{array}{c}\text { Adjusted } \mathrm{HR}^{\mathrm{b}} \\
(95 \% \mathrm{CI})\end{array}$ \\
\hline $\mathrm{Cis} / 5 \mathrm{Fu}$ & 1 (reference) & 1 & 1 \\
$\mathrm{Pac} / \mathrm{Car}(\mathrm{n}=87)$ & $0.45(0.28-0.72)$ & $0.47(0.28-0.80)$ & $0.57(0.33-0.97)$ \\
$p$-Value & 0.001 & 0.005 & 0.038 \\
\hline
\end{tabular}

Cis/5Fu: Cisplatin with 5-fluouracil; Pac/Car: paclitaxel with carboplatin; HR: hazard ratio; CI: confidence interval. aAdjusted for age, ECOG, stage, tumor location, and Charlson comorbidity index; bAdjusted for age, ECOG, stage, tumor location, Charlson comorbidity index, and surgical resection.

preferred regimen in the setting of neoadjuvant CCRT in patients with locally advanced EC, as it increased resectability of the post-CCRT tumor and showed longer survival even if tumor resection was not achieved.

Several studies have retrospectively compared the OS benefits of $\mathrm{Pac} / \mathrm{Car}$ and $\mathrm{Cis} / 5 \mathrm{Fu}$ in patients with locally advanced EC (8-11). Unfortunately, due to the retrospective nature of the studies, no definitive conclusion regarding the preference between the regimens can be drawn (18). In a definitive CCRT setting, Honing et al. have reported a comparable median OS (16.1 months in the Cis/5Fu cohort vs. 13.8 months in the Pac/Car cohort, $p=0.88$ ) based on their study in 102 patients with locally advanced EC in the Netherlands (19). While the OS was comparable between the groups, patients in the Pac/Car group presented significantly 




Figure 2. Survival outcome according to chemoradiotherapy with either cisplatin+5-fluouracil or paclitaxel+carboplatin. Cis/5Fu: Cisplatin with 5-fluouracil; Pac/Car: paclitaxel with carboplatin.

more cardiovascular and pulmonary comorbidities, which might have skewed the over survival of the Pac/Car group (19). In the neoadjuvant setting, Munch et al. have reported numerically non-significant survival difference (40.1 months in the Cis/5Fu group vs. 23.9 months in the Pac/Car group, $p=0.80$ ), based on a retrospective analysis (20). With only 51 patients in the study, the significance of this study result may have been compromised (20). On the contrary, our study was based on a prospective approach that showed a significant result where patients who received Pac/Car presented a better survival outcome than those receiving $\mathrm{Cis} / 5 \mathrm{Fu}$.

Trimodality therapy with neoadjuvant chemoradiotherapy followed by surgical resection is the standard treatment modality for patients with locally advanced EC $(21,22)$. However, not all patients would qualify for surgical resection after CCRT; the decision of a tumor board to proceed with surgery is mostly based on the tumor response and the clinical condition of patients after high-intensity CCRT. As reported previously, the response rates of patients to $\mathrm{Pac} / \mathrm{Car}$ have a range from $43 \%$ to $61 \%$, whereas those to $\mathrm{Cis} / 5 \mathrm{Fu}$ from $30 \%$ to $48 \%$ in patients with $\mathrm{EC}(6,11,18,20)$. Our study showed a significantly higher response rate in the $\mathrm{Pac} / \mathrm{Car}$ group compared to the $\mathrm{Cis} / 5 \mathrm{Fu}$ group $(75.9 \%$ vs. $57.1 \%, p=0.05$ ), which led to a higher probability of surgical resection and a better OS outcome in the Pac/Car group. The higher response rate of $\mathrm{Pac} / \mathrm{Car}$ may be due to several factors. First, the tolerability of patients to Pac/Car allows a timelier prescription in an outpatient setting without the need for hospitalization. Second, the lower toxicity profile of Pac/Car minimizes the event of dose de-escalation or treatment schedule modification; thus, treatment intensity is less likely to be compromised. In line with the findings of a previous study (19), our study showed a higher percentage of Pac/Car group patients who were able to complete the planned CCRT.

Most importantly, a higher response rate translates to greater resectability. Our study revealed that within the same regimen group, the OS would be prolonged after surgical resection. While survival was comparable between the groups after surgery, the higher response rate of the Pac/Car group resulted in a higher number of patients who were able to undergo surgery, thus contributing to an improved OS.

Our study also examined the survival of patients who did not undergo a surgery after the completion of CCRT. In the unresected cohort, the OS benefit of Pac/Car over Cis/5Fu was also better, as Pac/Car presented with a 2-year survival rate of $52.4 \%$ in contrast to Cis/5Fu's $19.2 \%$. This shows that Pac/Car should be the preferred initial regimen of choice as it is associated with longer survival regardless of tumor resection.

Previous retrospective studies have suggested better safety profiles of $\mathrm{Pac} / \mathrm{Car}$ compared to $\mathrm{Cis} / 5 \mathrm{Fu}$ in patients with $\mathrm{EC}$ undergoing CCRT (23). Our study revealed that $\mathrm{Cis} / 5 \mathrm{Fu}$ has a similar toxicity profile as Pac/Car and is associated with more non-hematological-related toxicities, especially mucositis. The higher toxicity rate of CCRT observed in our study represents the real-world experience in the clinical 


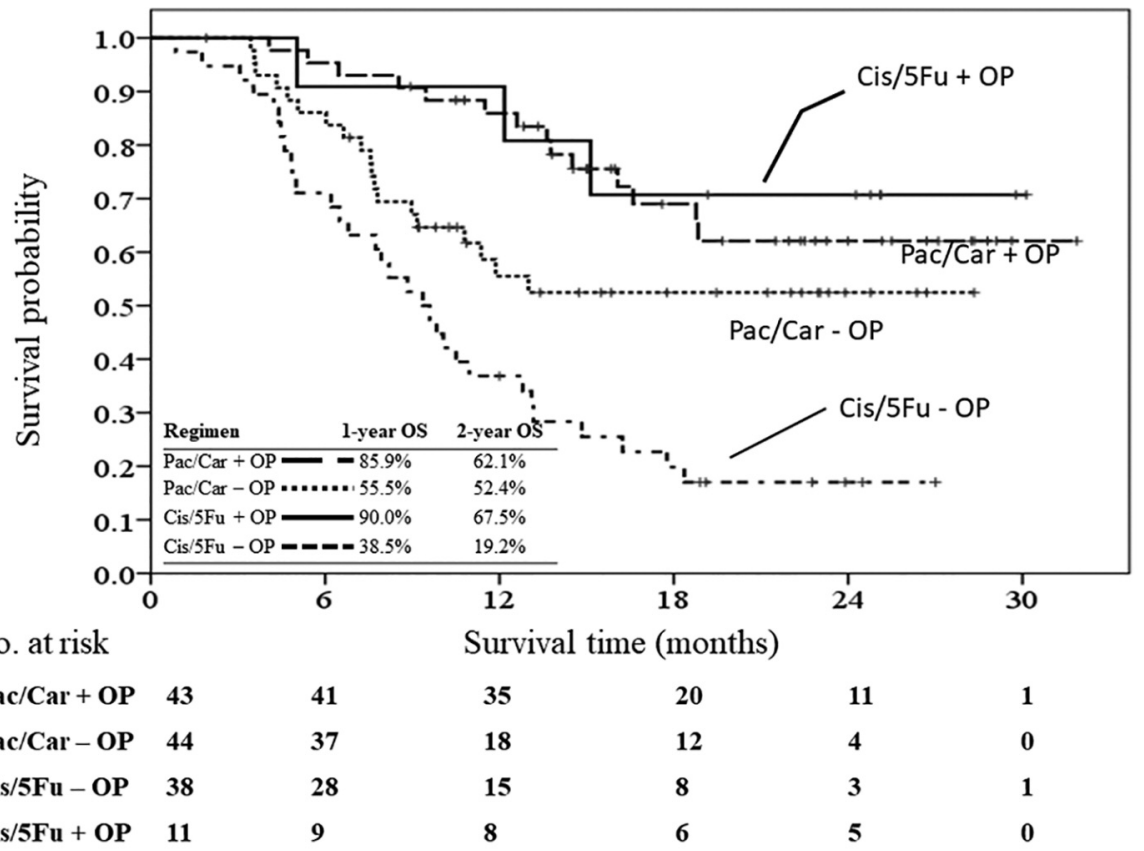

Figure 3. Survival outcome according to treatment group. Cis/5Fu: Cisplatin with 5-fluouracil; Pac/Car: paclitaxel with carboplatin; OP: operation.

practice, reminding clinicians to pay attention to patients with EC receiving CCRT, especially those receiving Cis/5Fu (23).

The difference in radiation dose and equivalent dosage of platinum between the regimens warrants further discussion. The higher radiation dose and cisplatin dosage in the $\mathrm{Cis} / 5 \mathrm{Fu}$ arm did not produce a better tumor response compared to the $\mathrm{Pac} / \mathrm{Car}$ arm; in contrast, it could have contributed to a significantly higher toxicity of CCRT in our study. Similar findings have been observed in the INT 0123 study, where patients with $\mathrm{EC}$ received concurrent $\mathrm{Cis} / 5 \mathrm{Fu}$ and two different radiation doses (64.8 vs. 50.4 Gy) (24). Survival outcomes and locoregional control were similar between the radiation dose groups, whereas high radiation doses were associated with higher toxicity profiles (24).

Instead of randomization, this study allowed patients to choose the regimen after we thoroughly explained to them the differences between the two regimens in terms of toxicities, financial cost, and treatment accessibility. Because the toxicity differences are well established, we believe that patients warrant the freedom to choose between the regimens. Unlike $\mathrm{Cis} / 5 \mathrm{Fu}$, $\mathrm{Pac} / \mathrm{Car}$ is not reimbursed by the national health insurance in Taiwan, and the choice of Pac/Car may be a reflection of patients' better economic and social support. Nevertheless, in our multivariate analysis, other variables that may reflect the socioeconomic status, such as marital status and educational background, did not show any statistical significance. Therefore, the influence of the economic status on this study's results may not be substantial. Regarding treatment accessibility, weekly
$\mathrm{Pac} / \mathrm{Car}$ seems to be a better and more convenient choice that could be administered in the outpatient department. All these reasons might partially explain the imbalance in the number of patients choosing the two regimens in our study. Although we adjusted for other important co-variables in the multivariate model to minimize the selection bias, it was still difficult to determine the statistical significance of all the patient characteristics in the two regimens.

This study is the largest prospective study to date in addressing the differences between $\mathrm{Cis} / 5 \mathrm{Fu}$ and $\mathrm{Pac} / \mathrm{Car}$ in the neoadjuvant treatment of locally advanced esophageal cancer. There are several limitations to this study. First, the non-randomization approach introduces an unforeseen bias to this study. Second, although the cohort was consecutively recruited and no statistical difference was observed among the evaluated patient characteristics, the unequal number of patients in the two groups may have affected the study results. Future studies should consider comparing Pac/Car and $\mathrm{Cis} / 5 \mathrm{Fu}$ in a randomized setting. In addition, to strengthen the statistical significance, a higher number of patients is required in the future.

In conclusion, our study showed that neoadjuvant chemotherapy regimen with $\mathrm{Pac} / \mathrm{Car}$ is associated with a better survival outcome compared to $\mathrm{Cis} / 5 \mathrm{Fu}$ in the treatment of locally advanced EC, as Pac/Car results in increased surgical resection rate after CCRT, and its survival benefit is pronounced even if tumor resection is not achieved. With an additional benefit of decreased toxicity profile, Pac/Car 
should be preferred over $\mathrm{Cis} / 5 \mathrm{Fu}$ in the neoadjuvant treatment of locally advanced EC.

\section{Conflicts of Interest}

The Authors declare no conflicts of interest.

\section{Authors' Contributions}

SPH, HSW, and CWC conceived and designed the study; HCY, YKY, and CPH acquired the data; HYS, HYW, LYC analyzed and interpretated the data; SPH, HSW, HYS, HCY, CWC Drafted the manuscript. All Authors read and approved the final version of the manuscript.

\section{Acknowledgments}

The Authors gratefully acknowledge the patients who participated in this study with support from the Cancer Center of Chang Gung Memorial Hospital.

\section{References}

1 American Cancer Society. Cancer Facts \& Figures 2020. Atlanta: American Cancer Society; 2020. Available at: https://www.cancer.org/cancer/esophagus-cancer/about/keystatistics.html [Last accessed on December 20, 2020]

2 Crosby T, Hurt CN, Falk S, Gollins S, Staffurth J, Ray R, Bridgewater JA, Geh JI, Cunningham D, Blazeby J, Roy R, Maughan T, Griffiths G and Mukherjee S: Long-term results and recurrence patterns from SCOPE-1: a phase II/III randomised trial of definitive chemoradiotherapy $+/-$ cetuximab in oesophageal cancer. Br J Cancer 116(6): 709-716, 2017. PMID: 28196063. DOI: 10.1038/bjc.2017.21

3 Kranzfelder M, Schuster T, Geinitz H, Friess H and Büchler P: Meta-analysis of neoadjuvant treatment modalities and definitive non-surgical therapy for oesophageal squamous cell cancer. $\mathrm{Br}$ J Surg 98(6): 768-783, 2011. PMID: 21462364. DOI: 10.1002/ bjs.7455

4 Ychou M, Boige V, Pignon JP, Conroy T, Bouché O, Lebreton G, Ducourtieux M, Bedenne L, Fabre JM, Saint-Aubert B, Genève J, Lasser P and Rougier P: Perioperative chemotherapy compared with surgery alone for resectable gastroesophageal adenocarcinoma: an FNCLCC and FFCD multicenter phase III trial. J Clin Oncol 29(13): 1715-1721, 2011. PMID: 21444866. DOI: $10.1200 / \mathrm{JCO} .2010 .33 .0597$

5 Cooper JS, Guo MD, Herskovic A, Macdonald JS, Martenson JA Jr, Al-Sarraf M, Byhardt R, Russell AH, Beitler JJ, Spencer S, Asbell SO, Graham MV and Leichman LL: Chemoradiotherapy of locally advanced esophageal cancer: long-term follow-up of a prospective randomized trial (RTOG 85-01). Radiation Therapy Oncology Group. JAMA 281(17): 1623-1627, 1999. PMID: 10235156. DOI: $10.1001 /$ jama.281.17.1623

6 van Hagen P, Hulshof MC, van Lanschot JJ, Steyerberg EW, van Berge Henegouwen MI, Wijnhoven BP, Richel DJ, Nieuwenhuijzen GA, Hospers GA, Bonenkamp JJ, Cuesta MA, Blaisse RJ, Busch OR, ten Kate FJ, Creemers GJ, Punt CJ, Plukker JT, Verheul HM, Spillenaar Bilgen EJ, van Dekken H, van der Sangen MJ, Rozema T, Biermann K, Beukema JC, Piet AH, van Rij CM, Reinders JG, Tilanus HW, van der Gaast A and CROSS Group: Preoperative chemoradiotherapy for esophageal or junctional cancer. N Engl J Med 366(22): 2074-2084, 2012. PMID: 22646630. DOI: 10.1056/NEJMoa1112088

7 Noronha V, Prabhash K, Joshi A, Patil VM, Talole S, Nakti D, Sahu A, Shah S, Ghosh-Laskar S, Patil PS, Mehta SA, Jambhekar N, Mahajan A and Purandare N: Clinical outcome in definitive concurrent chemoradiation with weekly paclitaxel and carboplatin for locally advanced esophageal and junctional cancer. Oncol Res 23(4): 183-195, 2016. PMID: 27053347. DOI: 10.3727/096504016X14537290676865

8 Blom RL, Sosef MN, Nap M, Lammering G, van den Berkmortel F, Hulshof MC, Meijer SL, Wilmink HW and van Berge Henegouwen MI: Comparison of two neoadjuvant chemoradiotherapy regimens in patients with potentially curable esophageal carcinoma. Dis Esophagus 27(4): 380-387, 2014. PMID: 24006852. DOI: 10.1111/dote. 12110

9 Sanford NN, Catalano PJ, Enzinger PC, King BL, Bueno R, Martin NE, Hong TS, Wo JY and Mamon HJ: A retrospective comparison of neoadjuvant chemoradiotherapy regimens for locally advanced esophageal cancer. Dis Esophagus 30(7): 1-8, 2017. PMID: 28475728. DOI: 10.1093/dote/dox025

10 Haisley KR, Hart KD, Nabavizadeh N, Bensch KG, Vaccaro GM, Thomas CR Jr, Schipper PH, Hunter JG and Dolan JP: Neoadjuvant chemoradiotherapy with concurrent cisplatin/5fluorouracil is associated with increased pathologic complete response and improved survival compared to carboplatin/paclitaxel in patients with locally advanced esophageal cancer. Dis Esophagus 30(7): 1-7, 2017. PMID: 28475724. DOI: 10.1093/dote/dox015

11 Huang C, Huang D, Zhu Y, Xie G, Wang H, Shi J, Jia B, Yuan $\mathrm{Y}$ and Zhang W: Comparison of a concurrent fluorouracil-based regimen and a taxane-based regimen combined with radiotherapy in elderly patients with esophageal squamous cell carcinoma. Transl Oncol 13(3): 100736, 2020. PMID: 32092670. DOI: $10.1016 /$ j.tranon.2019.12.008

12 Edge SB and Compton CC: The American Joint Committee on Cancer: the 7th edition of the AJCC cancer staging manual and the future of TNM. Ann Surg Oncol 17(6): 1471-1474, 2010. PMID: 20180029. DOI: 10.1245/s10434-010-0985-4

13 Kim HJ, Suh YG, Lee YC, Lee SK, Shin SK, Cho BC and Lee CG: Dose-response relationship between radiation dose and loco-regional control in patients with stage II-III esophageal cancer treated with definitive chemoradiotherapy. Cancer Res Treat 49(3): 669-677, 2017. PMID: 27737537. DOI: 10.4143/crt. 2016.354

14 van der Sluis PC, Schizas D, Liakakos T and van Hillegersberg R: Minimally invasive esophagectomy. Dig Surg 37(2): 93-100, 2020. PMID: 31096214. DOI: 10.1159/000497456

15 Mandard AM, Dalibard F, Mandard JC, Marnay J, Henry-Amar M, Petiot JF, Roussel A, Jacob JH, Segol P and Samama G: Pathologic assessment of tumor regression after preoperative chemoradiotherapy of esophageal carcinoma. Clinicopathologic correlations. Cancer 73(11): 2680-2686, 1994. PMID: 8194005. DOI: 10.1002/1097-0142(19940601)73:11<2680::aid-cncr28207 $31105>3.0 . c 0 ; 2-\mathrm{c}$

16 Hermanek P and Wittekind C: The pathologist and the residual tumor (R) classification. Pathol Res Pract 190(2): 115-123, 1994. PMID: 8058567. DOI: 10.1016/S0344-0338(11)80700-4 
17 Common Terminology Criteria for Adverse Events (CTCAE). Available at: https://ctep.cancer.gov/protocoldevelopment/ electronic_applications/ctc.htm [Last accessed on December 20, 2020]

18 Courrech Staal EF, Aleman BM, van Velthuysen ML, Cats A, Boot H, Jansen EP, van Coevorden F and van Sandick JW: Chemoradiation for esophageal cancer: institutional experience with three different regimens. Am J Clin Oncol 34(4): 343-349, 2011. PMID: 20562589. DOI: 10.1097/COC.0b013e3181d bbafe

19 Honing J, Smit JK, Muijs CT, Burgerhof JGM, de Groot JW, Paardekooper G, Muller K, Woutersen D, Legdeur MJC, Fiets WE, Slot A, Beukema JC, Plukker JTM and Hospers GAP: A comparison of carboplatin and paclitaxel with cisplatinum and 5-fluorouracil in definitive chemoradiation in esophageal cancer patients. Ann Oncol 25(3): 638-643, 2014. PMID: 24492674 DOI: $10.1093 /$ annonc/mdt589

20 Münch S, Pigorsch SU, Devečka M, Dapper H, Weichert W, Friess H, Braren R, Combs SE and Habermehl D: Comparison of definite chemoradiation therapy with carboplatin/paclitaxel or cisplatin/5-fluoruracil in patients with squamous cell carcinoma of the esophagus. Radiat Oncol 13(1): 139, 2018. PMID: 30068371. DOI: 10.1186/s13014-018-1085-z

21 Tepper J, Krasna MJ, Niedzwiecki D, Hollis D, Reed CE, Goldberg R, Kiel K, Willett C, Sugarbaker D and Mayer R: Phase III trial of trimodality therapy with cisplatin, fluorouracil, radiotherapy, and surgery compared with surgery alone for esophageal cancer: CALGB 9781. J Clin Oncol 26(7): 10861092, 2008. PMID: 18309943. DOI: 10.1200/JCO.2007.12.9593
22 Koshy M, Greenwald BD, Hausner P, Krasna MJ, Horiba N, Battafarano RJ, Burrows W and Suntharalingam M: Outcomes after trimodality therapy for esophageal cancer: the impact of histology on failure patterns. Am J Clin Oncol 34(3): 259-264, 2011. PMID: 20686405. DOI: 10.1097/COC.0b013e3181e841ce

23 Haj Mohammad N, Hulshof MC, Bergman JJ, Geijsen D, Wilmink JW, van Berge Henegouwen MI and van Laarhoven HW: Acute toxicity of definitive chemoradiation in patients with inoperable or irresectable esophageal carcinoma. BMC Cancer 14: 56, 2014. PMID: 24485047. DOI: 10.1186/1471-2407-14-56

24 Minsky BD, Pajak TF, Ginsberg RJ, Pisansky TM, Martenson J, Komaki R, Okawara G, Rosenthal SA and Kelsen DP: INT 0123 (Radiation Therapy Oncology Group 94-05) phase III trial of combined-modality therapy for esophageal cancer: high-dose versus standard-dose radiation therapy. J Clin Oncol 20(5): 1167-1174, 2002. PMID: 11870157. DOI: 10.1200/JCO. 2002.20.5.1167
Received July 2, 2021

Revised July 27, 2021

Accepted August 4, 2021 